logos_i_ethos_2016_(43)_numer_specjalny_2, s. 137-148

DOI: http://dx.doi.org/10.15633/lie.1965

Светлана Климова

\title{
Чаадаев о национальном самосознании: от диалогов с верховной властью к общественным дискуссиям
}

\begin{abstract}
Размышления о специфике русского национального самосознания, сформированного в зеркальных бликах истории, зачастую связывают с именем П. Я. Чаадаева, действительно

Светлана Климова - доктор философских наук, профессор Национального исследовательского университета «Высшая Школа Экономики», г. Москва. Email: sklimova@ hse.ru. «нечаянно» развернувшего широкую общественную дискуссию и маркировавшего известную оппозицию между славянофилами и западниками.
\end{abstract}

Чаадаев есть все нашей мысли, нашей историософии, а через нее - антропологии и социальной философии. Потому и поныне длящиеся споры о теоретическом содержании и социальном статусе русской философии: является ли она, по образцу европейской мысли, особого рода знанием, или же по преимуществу выражением национального самосознания, - это споры также о Чаадаеве - подлинном представителе русской мысли, предложившем в своих сочинениях образец нераздельно-неслиянного единства этих двух природ философии ${ }^{1}$.

1 А. Ермичев, А. Златопольская, П. Я. Чаадаев в русской мысли. Опьт историографии, в: П. Я. Чаадаев. Pro et contra. Личность Петра Чаадаева в оценке русских мыслителей и исследователей. Антология, ред. А. А. Ермичев, А. А. Златопольская, Санкт-Петербург 1998, c. 10. 
В русской гуманитарной традиции фигура П. Я. Чаадаева выглядит противоречиво: с одной стороны, преувеличенно, особенно в описании его уникального вклада в философию, с другой стороны, недооцененно, особенно в области «открытия» роли общественного мнения, во многом определявшем те или иные направления последующих культурно-исторических трансформаций. П. Я. Чаадаев стал жертвой одного из наиболее устойчивых стереотипов о «первых попытках нашего самосознания» (Н. Бердяев) лишь в славянофильской и западнической дискуссии в 30-е годы XIX века и в этой связи его пример - наглядная иллюстрация исторической гиперболизации роли отдельного человека (факта его творчества) в этом процессе.

Значение идей Чаадаева не в том, что он одним из первых поставил вопрос о специфике русского национального самосознания в контексте историософии и провиденциализма, но скорее всего в том, что публикация первого Философического письма мощно и в одночасье перевела регистр обсуждения уже давно существовавшей темы-проблемы на уровень широкой общественной дискуссии.

Проблема «первых попыток и первой идеологии» в определении русского национального самосознания была сформулирована значительно раньше «эпохи Чаадаева». Толчком к рефлексии на эту тему стал процесс институализации гуманитарного знания, перевод его в разряд государственно значимого. Создание Российской Академии в 1783 году «для разработки русского языка и литературы» было направлено на развитие отечественной культуры; в ее Уставе (Краткое начертание Императорской Российской Академии) официально декларировалось в качестве первейшей задачи определение таких понятий, как «национальная культура, русский язык» и «народное самосознание» (выражение ее первого председателя Екатерины Романовны Дашковой). Эти задачи должны были быть решены на основе научного развития русского языка, литературы, истории, материальных и духовных объектов культурного наследия народов империи. Соответственно по указу Екатерины II 
была очерчена и начала активно формироваться вся область гуманитарного знания в России, призванная ответить на призыв власти о сути национального самоопределения. Гуманитарные науки стали приоритетными для России в этот период. Их рупором стала Российская Академия, которая решала поставленные властью задачи, разными способами сконцентрировав внимание на зарождавшемся в XVIII - начале XIX вв. историческом и национальном самосознании.

Как известно, Е. Дашкова была одним из инициаторов формирования публичного пространства для дискуссий, организовав при академии чтение публичных лекций для освещения полученных результатов. Затем эта тема перетекла в интеллектуальное сообщество и стала предметом историософских дискуссий в журналах, аристократических салонах и философских кружках, а также художественной литературе и литературной критики, частных переписках. Мы помним, что Екатерина II создала типографии и журналы, ставшие главнейшим рупором общественного мнения и дискуссий, возможно, вопреки создателям.

Таким образом, Российская Академия оказалась легитимным каналом взаимосвязи между властью и обществом, наукой и критикой (сначала профессиональной, а потом общественной), выполняя уникальную функцию по консолидации различных интеллектуальных и социальных (за исключением низших) слоев общества.

Проблема национального самосознания, как конкретная идея, закладывалась, прежде всего, в рамках идеологического (правительственного) и интеллигентского (художественно-критического) мировоззрения и может быть проиллюстрирована на конкретных примерах творческого общения интеллигенции с властью. Первоначальные попытки выстраивались через литературные тексты, диалогические по форме, хотя и монологические по содержанию. Одним из ярких примеров стал диалог Екатерины Великой и Дениса Ивановича Фонвизина. В его известном тексте Несколько вопросов, могущих возбудить в умных и честных людях особливое 
внимание 2 заданы параметры уникального интеллектуального диалога писателя с императрицей, чьи ответы были размещены в этом же журнале. Диалог состоялся благодаря общей языковой культуре, высокому уровню образованности, общности понимания субъекта национального самосознания; в данном случае, таковым выступала дворянская интеллигенция.

В первой трети XIX века традицию связки интеллектуалывласть продолжил рассматривать пушкинский «Современник», в лице его редактора и авторов - А. С. Пушкина, В. Ф. Одоевского, Д. И. Языкова и др. Во втором номере за 1836 год тема «диалога с властью» стала сквозной и во многом магистрально выражающей отношение интеллектуалов того времени (в лице руководства журнала) к власти ${ }^{3}$. В этом номере была опубликована заметка Российская академия, упомянутый нами текст Фонвизина, правда, в несколько сокращенном виде (всего лишь 14 из его 21 вопроса) без дополнительных комментариев. Не менее знаменательной оказалась еще одна историческая публикация о диалоге интеллигенции с властью. Пушкин упомянул о чтении Александром I знаменитой Записки (1811 г.) Николая Михайловича Карамзина, в которой историк эмоционально-напряженно указывал на ключевые вопросы истории и судьбы России, обсуждал ее место в мировой истории, делая их объектом рефлексии не только со стороны историка, но и власти. К сожалению, этот диалог не получил должного развития и оценки как властью, так и современниками.

Таким образом, уже пушкинский «Современник», который вышел за несколько месяцев (июнь 1836 г.) до знаменитой публикации

2 В журнальном варианте: Вопросы и ответы с приобщением предисловия, «Собеседник любителей Российского слова, содержит разные сочинения в стихах и прозе Российских писателей» (Санкт-Петербург, иждивением Императорской Академии правительственное издание, выходившее под непосредственной редакцией Е. Р. Дашковой и Екатерины Великой).

См. Т. И. Краснобородько, Тема «литература и власть» на страницах второго тома «Современника», в: Пушкин: Исследования и материалы. Сборник научных трудов, т. 13, ред. Р. В. Иезуитов, Ленинград 1989, с. 128. 
Философического письма П. Я. Чаадаева в «Телескопе» (№ 15, октябрь 1836) 4 заострил внимание на тех проблемах и темах, которые были позже раскрыты у Чаадаева. Весь второй номер журнала можно назвать опережающим ответом на еще не озвученные чаадаевские вопросы.

Опубликовав вопросы Фонвизина, Пушкин как будто «показал пальцем» на текст, невольно позволяющий раскрыть читателю другие способы вопрошания, с указанием на конкретного адресата - власть, - и даже получать от них вполне конкретные ответы. Данной публикацией пушкинский «Современник» обнажил своеобразную «циклизацию» тем и идей русских интеллектуалов XVIII - начала XIX вв., соединив Фонвизина и Чаадаева в едином идейном хронотопе.

«Современник» убедительно свидетельствовал, что с властью возможно и даже необходимо говорить, обсуждать острые проблемы, однако без «озлобленного поучительства» и лучше - в эстетически завершенной, художественной и логически убедительной формах. Напечатав 14 (из 21) знаменитых вопросов Фонвизина, Пушкин как будто решил напомнить своим читателям не только известный текст XVIII века, но, возможно, завуалированно реконструировать некоторые пассажи чаадаевских идей, с которыми он был, скорее всего, знаком и с которыми вскоре ознакомится вся Россия; настолько удивительно конгениальными оказались их переклички. Даже чаадаевское обращение к даме, ответы на ее вопросы, как будто «срисованы» с фонвизинского текста - заочной дискуссии с первой дамой в государстве. Однако, разница в том, что Чаадаев писал не диалогический текст, не вопрошал, не

4 Не стоит забывать, что чаадаевское письмо, написанное на французском языке, как и многие его идеи, были известно образованному кругу российской интеллигенции. Лишь публикация на русском языке стала «выстрелом в темную ночь» (Герцен). Скорее всего, здесь роковую сыграли роль не только типографский шрифт журнала, но и русский язык, не приспособленный для обсуждения давно известных «французских» бунтарских тем. Французский язык, мирно демонстрировавший философские идеи автора, по-русски зазвучал угрожающе-бунтарски, непатриотично и обидно. 
обращался к равному или высшему; власть априори не могла выступить Другим его письма. Несмотря на то, что его респондентом является, как и у Фонвизина, женщина (аллюзия с Екатериной II); ее трудно назвать равным субъектом разговора. Если Фонвизин вопрошает даму, ищет у нее ответы на свою боль и недоумение, то Чаадаев поучает, учит жизни свою визави, он уверен в своем интеллектуальном превосходстве.

Не только формально, но и фактически между текстами имеется явное сходство в постановке проблем. Причем между текстами также можно протянуть метадиалог-размышление двух интеллектуалов: если Фонвизин спрашивает и указывает на больную тему, то Чаадаев уверен в ответах и надавливает на больное место для крайнего заострения ситуации. Например, для обоих национальное самосознание связано с ролью и статусом дворянства в России, и оба понимают эту роль «негативно». «Отчего главное старание большей части дворян состоит не в том, чтобы поскорее сделать детей своих людьми, а том, чтобы поскорее сделать их, не служа в гвардии, унтер-офицерами?»; «Отчего в век законодательный в этой части никто не помышляет отличиться?»; «Отчего у нас начинаются дела с великим жаром и пылкостью, потом же оставляются, а нередко и совсем забываются?»; «Отчего у нас не стыдно ничего не делать?»; «Отчего у нас спорят сильно в таких истинах, кои нигде уже не встречают ни малейшего сумнения?» - это фонвизинские вопросы, на которые как на констатацию печального факта смотрит Чаадаев.

Одна из самых прискорбных особенностей нашей своеобразной цивилизации состоит в том, что мы все еще открываем истины, ставшие избитыми в других странах и даже у народов, гораздо более нас отсталых. [...] Вам все еще приходится разыскивать, чем бы наполнить не жизнь даже, а лишь текущий день. [...] Ни у кого нет определенной сферы деятельности, нет хороших привычек, ни для чего нет правил, нет даже и домашнего очага. [...] У нас совсем нет внутреннего развития, естественного прогресса; прежние идеи выметаются 
новыми, потому, что последние не происходят из первых, а появляются у нас неизвестно откуда ${ }^{5}$.

Таким образом, данный метадиалог маркирует культурный сдвиг в размышлении о природе национального самосознания и истории, двигая разговор от диалогов с властями к широкому интеллектуальному - литературному обсуждению темы, смещенной в русло общественной дискуссии. Разница между эпохальными вопросами и эпохальным ответом налицо. Если Фонвизин остается в традициях единой культурной среды, позволяющей сохраняя всю значимость вертикали власти, все-таки чувствовать себя с ней в едином поле интерпретаций, то Чаадаев - открытый оппозиционер; он уже знает, чем практически заканчиваются разговоры подобного рода. Поэтому - он не вопрошает, а декларирует, не пытается разговаривать, а раздает оценки и поучает. Он сознательно дистанцирует себя от власти, маркируя свой особый статус учителя и пророка. Тем самым он присваивает себе статус власти - роль властителя дум, став образцом духовного реформатора, а свое визави - творимое им же коллективное со-общество, которое становится не равноправным участником диалога, а «некоей коллективной дамой», трепетно внимающей громким словам Учителя и создающей на этой основе свое - а в действительности общественное мнение.

Поскольку отношение Пушкина к Чаадаеву и его письму хорошо известно, то, скорее всего, мы не ошибемся, предположив, что роль и значение последнего он оценивает примерно в тех же позитивных эпитетах, что и роль Фонвизина в историческом диалоге с властью. В частности, в своем письме Чаадаеву он резюмирует:

Поспорив с вами, я должен вам сказать, что многое в вашем послании глубоко верно. Действительно, нужно сознаться, что наша общественная жизнь -

5 П. Я. Чаадаев, Философические письма, в: П. Я. Чаадаев, Полное собрание сочинений и избранные письма, т. 1, Москва 1989, с. 323-324, 326. 
грустная вещь. Что это отсутствие общественного мнения, это равнодушие ко всякому долгу, справедливости и истине, это циничное презрение к человеческой мысли и достоинству - поистине могут привести к отчаянию. Вы хорошо сделали, что сказали это громко 6 .

В данном случае - громко сказанное слово в России, как правило, ведет к духовному пробуждению тех, к кому оно было обращено. Пушкин прямо называет субъекта: это дворянское (позже и разночинское) общество, которое стоит на пороге формирования своего собственного мнения по различным вопросам и своего особого статуса.

Таким образом, Чаадаев не был первым, кто поставил вопрос о национальном самосознании и истории России; его появление также не было неожиданностью для русских интеллектуалов, которые видели в действиях самой власти возможность скорого появления «чаадаевщины». Например, П. А. Вяземский в Проекте письма C. С. Уварову красноречиво показал противоречивую природу поведения власти, на примере конфликта Карамзина и университетского преподавателя Н. Устрялова. Он показал, как первого - подлинного патриота, который всегда был верен самодержавию, но как историк не щадил «самодержца перед неизбежным зерцалом потомства» - ошельмовали и «низвергли» и критики, и власть, а второго университетского профессора, насмешливо отказывающего России в уникальности, праве на свою историю, высмеявшего Н. Карамзина с его идеей наличия «русской истории как таковой», защитившего на эту тему диссертацию и широко вещавшего о русской «недалекости» в студенческой аудитории - не только не наказали; напротив, его всячески поощряло Министерство просвещения.

Исторический скептицизм, терпимый и даже поощряемый Министерством просвещения, неминуемо довел до появления в печати известного письма

6 А. С. Пушкин, Письмо П. Я. Чаадаеву от 19.02 .1836 г., в: П. Я. Чаадаев. Pro et contra, op. cit., c. 75 . 
Чаадаева, помещенного в «Телескопе». Напрасно искать в сем явлении тайных пружин, движимых злоумышленными руками. Оно просто естественный созревший результат направления, которое дано нашей критике. Допущенное безверие к писанному (истории Карамзина - С. К.) довело до безверия к действительному ${ }^{7}$.

Однако роль Чаадаева в нашей культуре велика. Он стал зачинателем нового формата дискуссий о русской истории, ее национальном самосознании и перспективах, переведя обсуждение с официального (власть) - литературного (журнального) и научного (университетского) уровней на общественный; в тоже время, он оказался одним из творцов этого самого публичного пространства, вовлекая в него самые широкие слои образованного (читающего) и полуобразованного общества, которое после Чаадаева стало восприниматься как особая интеллектуальная сила, способная к самостоятельным суждениям и поступкам в области созидания и укрепления национальной истории и самосознания. Чаадаев, подобно Герцену, разбудил общество своим «выстрелом», кинув ему перчатку для создания нового формата развития через общественное мнение. О «качестве» такого общества выразительно заметил И. И. Панаев: «Статья, вследствие которой запрещался журнал, приобретала популярность не только между всеми грамотными и читающими людьми, но и даже полуграмотными, которые придавали ей Бог знает какие невежественные толкования» ${ }^{8}$.

Так возник феномен «проклятой чаадаевщины» (П. Киреевский), который в своей одноминутной премудрости зачеркнул историческую память, заполняя «свободное» место всевозможными сказками, наполненными бессмысленной гордынью, смешанной с патологическим самобичеванием и юродством, что всегда так трафит «общественному мнению». Сформировав общественную полемическую op. cit., c. 119.

П. А. Вяземский, Проект письма к С. С. Уварову, в: П. Я. Чаадаев. Pro et contra,

8 И. И. Панаев, Литературные воспоминания, Ленинград 1928, с. 184-185. 
среду вместо диалога с властью, Чаадаев создал пространство интеллектуальной оппозиции, зачастую упивающуюся популистскими теориями, наивно принимаемыми полуобразованной публикой за «истинные в последней инстанции». Оппозиционность не только к власти, но и к своему народу, своей истории, культуре, родному языку становится новой устойчивой формой интеллигентской «любви к родине», о которой так мечтал Чаадаев, однако, не скрепившей этим общество, но расколовшей его окончательно. Теперь, чтобы быть популярным, успешно продавать свои труды, громко звучать интеллектуал должен был превратиться в интеллигента, то есть «стать в оппозицию», начать подрывать (через литературу, философию, публицистику или революционные практики) устои собственного государства и общества.

Правительство не нашло ничего лучшего, как «замолчать» факт чаадаевской публикации, не отвечая недостойному оппоненту.

Отвечать на произведения такого рода - было бы унизить священное дело нашей народности. Кто уважил впечатление, произведенное этой пьесой над читателями, тот, конечно, убедится в бесполезности опровержения и будет смотреть с молчанием презрения на тщетное покушение ума нездравого и сожаления достойного 9.

Молчаливое презрение дорого стоило и власти, и нашему народу. Теоретическое позерство, историческое сочинительство, фразерская вакханалия, спровоцированные им, стали основаниями для разгула политического мифотворчества и позднейших практических революционных событий, а также вечного противопоставления «наших и не наших» идей и ценностей в одной стране и разных культурах.

Вместе с тем, в своей категоричности Чаадаев, как в лице властей, так и с точки зрения общественного мнения (сформированного под его же влиянием), оказался «виновным» за многие нерешенные

9 Проект обиииального опровержения статьи Чаадаева, в: П. Я. Чаадаев. Pro et contra, op. cit., c. 73 . 
проблемы в отечестве; образно говоря, его фигура приобрела черты сакральной жертвы, принеся которую, пусть и символически в ходе изоляции «сумасшедшего» от нормальных, власть была на время «спасена» от революционных взрывов, так как общество подхватило полемический накал письма и обнажило дискуссионное пространство по поиску собственной идентичности, направив энергию на литературное творчество и публицистку, а не на революцию и войну.

При этом власть, отказавшись от участия в этих диалогах и совместных обсуждениях ключевых проблем истории и ментальности России с интеллектуальной и творческой элитой, компенсировала этот просчет идеологическими манипуляциями, управлением общественным мнением, используя его как своеобразный инструмент для «налаживания связей» с разными группами общества, подбрасывая ему идеи и символы. В переломные моменты именно интеллигенты внедряли то патриотический дискурс, то православный, то национальный, то интернациональный, выполняя неведомые им заказы властных структур, или же стремясь занять место власти не фигурально (как Чаадаев), но практически и исторически конкретно и реально.

\section{Библиография}

Вяземский П. А., Проект письма к С. С. Уварову, в: П. Я. Чаадаев. Pro et contra. Личность Петра Чаадаева в оценке русских мыслителей и исследователей. Антология, ред. А. А. Ермичев, А. А. Златопольская, Санкт-Петербург 1998, c. $114-124$.

Ермичев А., Златопольская А., П. А. Чаадаев в русской мысли. Опыт историографии, в: П. Я. Чаадаев. Pro et contra. Личность Петра Чаадаева в оценке русских мыслителей и исследователей. Антология, ред. А. А. Ермичев, А. А. Златопольская, Санкт-Петербург 1998, с. 7-42.

Краснобородько Т. И., Тема «литература и власть» на страницах второго тома «Современника», в: Пушкин: Исследования и материальы. Сборник научных трудов, т. 13, ред. Р. В. Иезуитов, Ленинград 1989, с. 122-133. 
Панаев И. И., Литературные воспоминания, Ленинград 1928.

Проект официального опровержения статьи Чаадаева, в: П. Я. Чаадаев. Pro et contra. Личность Петра Чаадаева в оценке русских мьслителей и исследователей. Антология, ред. А. А. Ермичев, А. А. Златопольская, Санкт-Петербург 1998, с. 73. Пушкин А. С., Письмо П. Я. Чаадаеву от 19.02 .1836 г., в: П. Я. Чаадаев. Pro et contra. Личность Петра Чаадаева в оценке русских мьслителей и исследователей. Антология, ред. А. А. Ермичев, А. А. Златопольская, Санкт-Петербург 1998, c. 74-75.

Чаадаев П. Я., Философические письма, в: П. Я. Чаадаев, Полное собрание сочинений и избранные письма, т. 1, Москва 1991, с. 320-440. 